\title{
Household Use of Composted Manure and Phosphorous-Free Fertilizers: Feeling Good versus Doing Good
}

\author{
Laura McCann', Dong Won Shin² \\ ${ }^{1}$ Department of Agricultural and Applied Economics, University of Missouri, Columbia, MO, USA \\ ${ }^{2}$ Korea Environment Institute, Sejong, South Korea \\ Email: McCannL@missouri.edu
}

How to cite this paper: McCann L., and Shin, D.W. (2018) Household Use of Composted Manure and Phosphorous-Free Fertilizers: Feeling Good versus Doing Good. Journal of Environmental Protection, 9, 140-157. https://doi.org/10.4236/jep.2018.92011

Received: January 10, 2018

Accepted: February 24, 2018

Published: February 27, 2018

Copyright (c) 2018 by authors and Scientific Research Publishing Inc. This work is licensed under the Creative Commons Attribution International License (CC BY 4.0).

http://creativecommons.org/licenses/by/4.0/

\section{(c) (i) Open Access}

\begin{abstract}
Increasing urbanization has led to increasing impermeable surfaces and use of lawn care products. Phosphorous $(\mathrm{P})$ is a major pollutant in freshwater systems, leading to eutrophication, harmful algal blooms and hypoxia. An important source is runoff from urban areas so reducing use of $\mathrm{P}$ fertilizers by homeowners would be helpful. This study examines the use of two alternative fertilizer sources in an urbanizing watershed in the Midwest, organic fertilizer/composted manure and P-free fertilizer. A mail survey of households was conducted, resulting in a $44 \%$ effective response rate. The adoption rates were relatively high ( $31 \%$ and $23 \%$ respectively) compared to those found in previous work for rain gardens and rain barrels. Probit regression results found that adoption of both practices was higher among those who tested their soil, knew the watershed concept, and spent more than 10 hours per month gardening. Results for use of composted manure imply that adopters do not view this as fertilizer, which may result in buildup of $\mathrm{P}$ levels in the soil over time. Respondents who indicated that water quality was more important than economic development were more likely to use P-free fertilizers. Significant demographic factors for organic fertilizer were somewhat surprising; those with two years of college were more likely to adopt than those with a four-year degree and those with household income of $\$ 50,000-75,000$ were more likely to adopt than those with an income of $\$ 75,000-100,000$. No demographic factors were important for P-free fertilizers.
\end{abstract}

\section{Keywords}

Adoption, Lawn Care, Organic Fertilizer, Phosphorous, Water Quality 


\section{Introduction}

Urbanization has increased in the US in recent years [1] [2], resulting in decreased wetlands and increased impervious surfaces which result in increased stormwater runoff. This can increase flooding and degrade aquatic habitats due to high peak flows. In addition, these changes to the landscape also increase water pollution due to increased nutrients and pesticides in the runoff due to both increased applications and water flows.

Phosphorous (P) is a problem in the Chesapeake Bay as well as the Great Lakes, where an algal bloom in Lake Erie affected water supplies in Toledo, Ohio in 2014. While much of the attention is focused on agriculture as the main nonpoint $\mathrm{P}$ source, households are also part of the problem. In the Chesapeake Bay, urban/suburban runoff was a major contributor of $\mathrm{P}$ and the only one that was increasing [3]. While the amount of land in lawns is small relative to cropland, fertilizer use per acre is higher [4], up to 10 times as high in one study [5]. A number of studies looking at urban fertilizer use have found that most homeowners apply fertilizer without having done a soil test to determine nutrient needs [6] [7] [8]. In Missouri, actual soil tests in the Springfield area [7] and Boone County (which includes Hinkson Creek watershed) [9] found that soil P and potassium (K) levels were high. Fifty-four percent of Boone County lawn and garden soil samples had high or very high $\mathrm{P}$ levels, and 66 percent had high or very high $\mathrm{K}$ levels. Homeowners also imply "a lot of minds to change"; it is estimated that 38 million people overfertilize their lawns [10].

This study examines the factors affecting household adoption of two fertilizers that may have environmental benefits: composted manure/organic fertilizer and P-free fertilizer, which are described below. While many people may view organic products as being environmentally superior, P-free fertilizers actually address the environmental problem of algal blooms, so comparing these products is important. To our knowledge, this is the first study to examine the use of organic fertilizers by households and the first to compare these two products.

Livestock manure is a major contributor to agricultural runoff that causes water quality problems [11] [12] [13]. Agriculture has become more specialized, resulting in some farmers with no livestock and others with livestock but essentially no land for manure application [14]. Interest in manure transfers is increasing due to fertilizer costs, renewable energy, and water quality issues (e.g. [15] [16]). New uses for manure can be win-win opportunities for livestock farmers, new users, and the environment. While there is increasing interest by crop farmers in using manure as a source of $\mathrm{P}$, nitrogen $(\mathrm{N})$, micronutrients, and organic matter, another potential market is households. If manure nutrients from livestock farmers are in excess of on-farm crop needs, and if the manure used off the farm substitutes for commercial fertilizer; nutrient pollution may be reduced. However, livestock manure typically has higher $\mathrm{P} / \mathrm{N}$ ratios than needed by crops or lawns so applications that are based on $\mathrm{N}$ will lead to an accumulation of $\mathrm{P}$ in the soil, unless complemented with a commercial N source. Proper composting 
of manure kills weed seeds and pathogens but some of the ammonia-N is lost, exacerbating this problem. In addition, the composition of manure is variable. Many gardening and home improvement stores sell composted manure as an organic alternative to commercial fertilizer.

P-free fertilizers for home use were developed because established lawns usually need no additional $P$. Under these circumstances, balanced fertilizers (containing N, P and $\mathrm{K}$ ) can result in greater $\mathrm{P}$ runoff from urban landscapes [17]. In the previous decade, there were educational campaigns such as the one by the Lawn to Lake Consortium that used the phrase "Don't 'P' on your lawn". There have also been legislative efforts. Eleven states have passed laws that limit the use of P-containing fertilizers on lawns except for establishing new turf or if a soil test indicates a need for P. Minnesota passed their law in 2002 but most of the other states passed their laws in 2010 or 2011 [18]. Scott's Miracle-Gro removed $\mathrm{P}$ from their Turf-Builder products in 2013, and no further laws have been passed since then. Consumers in other states, such as Missouri, can choose to buy commercial fertilizers without $P$ if they know that the middle number on the fertilizer bag indicates the $\mathrm{P}$ content or if they read the label carefully. These fertilizers are not organic, however they can improve water quality by reducing $\mathrm{P}$ runoff [19].

These two alternative fertilizers for home use have different characteristics. While both have the potential to improve water quality by reducing overall nutrient pollution, composted manure is a natural product that can be produced organically, and which has a variety of on-site benefits for gardens, while P-free fertilizers are a commercial, chemically-produced fertilizer product. Therefore we hypothesize that the factors affecting adoption of these products, such as demographic factors, environmental attitudes, gardening habits, and information sources, may differ. In the next section, the literature is reviewed to develop specific hypotheses which are used to build the conceptual model. The hypotheses are tested using mail survey data from an urbanizing watershed in Columbia, Missouri.

This research can be used to increase adoption rates of these practices by improving educational and advertising efforts and the design of new products. Since a number of states have policies restricting the sale of fertilizers with $\mathrm{P}$ for home use, this may also be useful information for other states that are considering such policies. This research also supplements the relatively meagre literature on residential adoption of environmentally-friendly practices for lawns and gardens.

\section{Literature Review}

Most research on adoption of environmental practices to improve water quality has focused on farmers instead of households. Economics and sociology both examine adoption and diffusion of innovations in general and conservation practices in particular (see reviews by [20] [21] [22] [23]). The literature shows 
that perceived characteristics of the practice (e.g. profitability, relative advantage), adoption of complementary practices, as well as characteristics of the farm and farmer are important.

Regarding household landscape management practices, demographic characteristics affect adoption. Higher incomes typically are associated with higher adoption probability (e.g. [24] for rain barrels, [25] for chemical use on lawns, [26] for water conservation practices, [27] for appropriate disposal of pet waste and grass clippings, and [28] for fertilizer). A study that specifically examined adoption of $\mathrm{P}$-free fertilizers found that it was positively influenced by income level [27].

While the literature on farmers often finds that adoption of best management practices (BMPs) increases with education and decreases with age, studies of households often find insignificant effects. Reference [27] found that adoption of appropriate management of grass clippings increased with education level, but that it did not have an effect on adoption of P-free fertilizers. Reference [24] found no effect of education on rain barrel adoption, but [26] found more education increased use of water conservation practices both inside and outside the home. Studies examining age and household practice adoption typically find insignificant relationships (e.g. [27] on lawn care BMPs, [24] on rain barrels, [29] on rain gardens).

Studies often find that women are more likely than men to have pro-environmental attitudes (e.g. [30]) and to adopt environmental practices. Reference [29] found that men were more likely to have never heard of rain barrels than to adopt them but that there was no effect for rain gardens. Men were less likely to correctly dispose of grass clippings but there was no effect on the other BMPs (including P-free fertilizer) examined by [27].

In addition to demographic variables, gardening interests and complementary practices may be relevant. Serious gardeners have been shown to be more likely to adopt stormwater management [29] [31] since they would tend to be more aware of the practices and may get utility from trying them out. Gardeners typically want a landscape that is aesthetically pleasing which may be in conflict with their environmental preferences [25] [32]. Reference [29] found that those who watered their lawn as needed to keep it green were more likely to have adopted rain gardens. However, concern about the appearance of rain barrels and rain gardens was not significant for either practice, all else equal. Compatibility with other features was a concern that limited adoption of rain barrels in that study. Reference [33] found that water conservation behaviors that required permanent changes to the landscape had lower adoption intensions. Related landscape management practices, such as soil testing or using a lawn care service, may affect adoption rates [34]. Reference [29] found that use of a lawn care service was negatively associated with adoption of rain barrels.

Environmental knowledge and attitudes both affect adoption intentions of household BMPs [6] [35]. Adoption of residential BMPs may be increased by 
knowledge regarding BMPs and the existence of a watershed management plan [10] [29] [36]. Reference [27] did not find an effect of knowledge about a watershed management plan, however a knowledge scale developed from knowledge of all the BMPs examined was highly significant for all practices, including the use of P-free fertilizer. Reference [24] showed that awareness of the effects of rain barrels had a positive impact on their adoption, while [29] found that among adopters, none doubted the water quality benefits of rain barrels.

Pro-environmental attitudes and trusting information from environmental organizations, can also impact adoption of BMPs. However, [30] found that knowledge of horticultural practices and adoption of them was not linked to general environmental attitudes. According to [37], if households trust information sources, they would be more likely to follow the group's recommendations regarding environmental practices for the landscape. Reference [29] found that people who trusted environmental groups very much were more likely to have adopted rain barrels.

\section{Conceptual Model}

Given the different characteristics of these two practices, we examined whether the factors affecting adoption differed between the two. In this study, households are assumed to choose the fertilizer product(s) that maximize their utility. As explained later, homeowners who did not apply any fertilizer were eliminated from the dataset so the comparison in each case is with use of standard commercial fertilizers.

From the literature on the effects of demographic characteristics, we expect the likelihood of adoption of both practices to increase with education, and to be lower for men compared to women. While neither of these practices is especially expensive, and neither requires permanent changes to the landscape, and thus neither requires additional financial outlays, the opportunity cost associated with higher incomes may have an effect. P-free fertilizers are a concentrated source of nitrogen, are easy to use, and widely available so those with higher incomes and thus a higher opportunity cost of time, would not be more likely to use P-free rather than balanced fertilizer. (P-free fertilizers are not more expensive than balanced commercial fertilizers). Organic fertilizers on the other hand are more cumbersome and less available. Thus, contrary to typical analyses, we expect households with higher incomes to be less likely to adopt organic fertilizer and for there to be little or no effect on P-free fertilizers since time requirements would be similar in that case.

In addition to demographic factors that are often related to adoption, we include knowledge of the watershed concept since people interested in environmental issues may be more likely to have learned about it, and knowing that information, be more likely to adopt BMPs. Since this is a fairly general indicator, we expect it would probably positively affect adoption of both practices. A more specific indicator of attitudes toward water quality versus economic development would 
be expected to have greater impact on P-free fertilizer use since this product directly affects water quality and little else. Another indicator of pro-environmental attitudes is whether they trust environmental groups very much. We expect this to be more important for organic fertilizer since some of these people may distrust any commercial fertilizer.

Other landscape management practices may also have effects on adoption. We expect that people who fertilize more often than recommended by Extension to be less likely to adopt either practice. We expect a positive correlation with use of soil testing for both practices but for the effect to be stronger for P-free fertilizer use since households would have good information on current soil P levels as well as specific recommendations for $\mathrm{P}$ applications. Composted manure has a variety of positive impacts on yards and gardens, such as improving soil tilth and providing trace elements, which are not obtained from typical commercial fertilizers. Serious gardeners, as measured by time spent gardening, may be more aware of the additional benefits provided by composted manure and thus more likely to use it, however these households would also be more likely to be aware of the availability of P-free fertilizers. We expect time spent gardening to increase adoption of both practices relative to balanced commercial fertilizers but for the effect on compost to be stronger.

On the other hand, households who hire mowing and chemical application services would be expected to gain less utility from yard and lawn care and thus to be less aware of both products and less likely to adopt them. Residents preferred sources of fertilizer information may also affect adoption. Those who distrust conventional sources of fertilizer information, such as commercials and store employees, would be more likely to adopt organic fertilizer, but we expect little effect for P-free fertilizers.

\section{Data and Methods}

We conducted a mail survey of Columbia, Missouri households in spring of 2014. A random sample of 2000 names and addresses was obtained from Survey Sampling Incorporated for three zip codes $(65201,65202$, and 65203) that included the City of Columbia as well as nearby rural and suburban residents. Using ZIP codes to create the sample is relatively simple and may cause less sample clustering [38]. We asked that the sampling eliminate multi-family housing to focus on detached homes with yards. The design of the survey and the survey process followed the Dillman methodology [39]. (For more information on the survey, see [29]).

The survey was designed to examine adoption of a range of environmental practices relevant to households, including organic fertilizer (composted manure was a second term provided) and phosphate-free (P-free) fertilizer. The survey instrument included questions that were modified from [40] to measure environmental attitudes, and from [41] to examine lawn care practices. Some other questions were from the Social Indicators for Planning and Evaluation System 
(SIPES) [42]. The cover letter asked the person most responsible for lawn care to complete the survey.

To improve the survey, we pre-tested it using respondent debriefing since researchers are able to discuss the survey with respondents immediately after they take the survey in order to better understand how they interpreted the questions [43]. The survey was modified somewhat after discussion with two groups of a dozen volunteers. That version of the survey and other correspondence was approved by the Institutional Review Board of the University of Missouri.

The Dillman Total Design Method [39] consists of many techniques designed to increase response rates and the validity of the responses. In addition to multiple mailings of the survey packet, we also included a magnet with a picture of Hinkson Creek and the county Extension Service's website ${ }^{1}$. The effective response rate was calculated by first removing 200 cases where people had moved or died as well as 27 cases for whom the survey was not relevant, such as those with no lawn. Of the remaining 1773 questionnaires, 783 were completed and returned resulting in an effective response rate of $44.1 \%$.

The dependent variables, use of organic fertilizer and P-free fertilizer, are dichotomous variables $(1=$ currently use it, and $0=$ otherwise, including responses of "know how to use it, but not using it", "somewhat familiar with it, but not using it", and "never heard of it"). Explanatory variables are created from the survey data, similar to those of [29].

The dummy variable for knowledge of the watershed concept is "Know what it means" while the base is created by combining "I have heard of it but I'm not sure what it means", and "Never heard of it". Another variable measured their level of agreement with the sentence "It is important to protect water quality even if it slows economic development", using a Likert scale ( 1 = Strongly disagree to $5=$ Strongly agree). Responses of 1,2 , or 3 are used as the base category and responses of 4 or 5 are combined to create the agree dummy variable. Attitude about neighbors was evaluated by their level of agreement with the statement "It is important to me that my neighbors think I have a nice lawn", using the same Likert scale. The agree dummy variable again consists of responses 4 or 5. Environmental attitudes are measured by the level of trust in environmental groups as information providers about soil and water issues; responses of not at all, slightly, and moderately form the base, while very much is used as the dummy variable.

For household's lawn care behavior variables, four categories of frequency of fertilizing their lawn are combined to reflect three subcategories: never, 1 to 2 times per year (base category), and more than 3 times per year. Frequency of watering lawn responses were: "as needed to keep it green", "infrequently in summer", "only in severe drought" and "never water". The low watering variable consists of the last two options while the first two form the base in the regression. The lawn care service variable includes three categories: no service (base ${ }^{1}$ See [29] for specific information on the timing and content of mailings. 
category), service just for mowing, and a service that involves chemical use including fertilization and pest control. Household gardening behavior was assessed by asking about the "average hours a month spent during the March to November growing season". The four possible response categories were combined to form a base category of 0 - 10 hours and a dummy variable of greater than 10 hours. Use of a soil test is a dichotomous variable ( $1=$ currently use it, and $0=$ do not use).

For demographic variables, a male (vs female) dummy variable for gender is used. Annual household income consists of; less than $\$ 24,999, \$ 25,000$ - $\$ 49,999$, $\$ 50,000$ - $\$ 74,999$ (base category), $\$ 75,000$ - $\$ 99,999$ and more than $\$ 100,000$. Education level responses include: high school diploma or GED, 2 year college degree, 4 year college degree (base category), and post-graduate degree. Homeownership is a dummy variable with renter as the base. Location or residence variables include living in the city of Columbia (base category), suburban, and rural.

Most important fertilizer information source options included eight categories: Not applicable/do not fertilize, TV/newspaper commercial, Internet information, Information on the label/package, Employees in store, Professional/extension service (base category), Neighbors/family/friends, and other. Those checking other were asked to specify the source and the most common response was lawn care service employees.

We removed 66 respondents (about ten percent of usable surveys) who we believe never use fertilizer of any kind, i.e. if they say they never fertilize their lawn, they do not use a service for fertilization, and they also indicate that information on fertilizer is not applicable to them. The base in the regressions is thus implicitly typical commercial fertilizer.

Due to the dichotomous nature of the dependent variables, a bivariate probit model is employed. The independent variables were categorical or used Likert scales and were recoded into dummy variables for the regression analysis. Given a variety of factors that are hypothesized to influence adoption likelihood for homeowner $i,\left(x_{i}=x_{1}, x_{2}, x_{3}, \cdots, x_{k}\right)$, the probability of adoption is denoted as $p_{i}=P\left(Y_{i}=1 \mid x_{i}\right)$, which is assumed to be given by the standard normal distribution $\Phi\left(x^{\prime} \beta\right)$ for probit models [44]. If unobservable error terms are independent, we can obtain consistent estimates by using this single-equation probit model. However, adoption decisions for composted manure are likely not independent of the adoption of $\mathrm{P}$-free fertilizer. Therefore, the single equation probit regression may not be efficient since it ignores the correlation between the error terms [44]. The bivariate probit model overcomes this problem by the joint prediction of adoption decisions. Thus, we apply the bivariate probit model in order to test this correlation. The data were analyzed using STATA 13. We first report the summary statistics since the adoption rates themselves are also of interest.

\section{Results and Discussion}

As shown in Table 1, about 31 percent of respondents indicated they used "organic 
Table 1. Summary statistics.

\begin{tabular}{|c|c|c|c|c|c|c|c|}
\hline \multirow{3}{*}{ Variable } & \multirow{3}{*}{ Obs } & \multirow{3}{*}{ Mean } & \multirow{3}{*}{ Std. Dev. } & \multicolumn{2}{|c|}{ Organic fertilizer } & \multicolumn{2}{|c|}{ P-free fertilizer } \\
\hline & & & & Adopters & Non-adopters & Adopters & Non-adopters \\
\hline & & & & Mean & Mean & Mean & Mean \\
\hline Organic fertilizer & 590 & 0.308 & 0.462 & 0.308 & 0.692 & 0.526 & 0.240 \\
\hline P-free fertilizer & 581 & 0.234 & 0.424 & 0.399 & 0.159 & 0.234 & 0.766 \\
\hline \multicolumn{8}{|l|}{ Environmental Knowledge and Attitudes } \\
\hline Knowledge of watershed & 601 & 0.637 & 0.481 & 0.772 & 0.575 & 0.754 & 0.598 \\
\hline Importance of water quality & 610 & 0.813 & 0.390 & 0.857 & 0.792 & 0.868 & 0.796 \\
\hline Concern about neighbors' opinions & 605 & 0.430 & 0.495 & 0.333 & 0.478 & 0.425 & 0.436 \\
\hline Trust env. group very much & 584 & 0.175 & 0.380 & 0.273 & 0.125 & 0.215 & 0.151 \\
\hline
\end{tabular}

\section{Yard Management Behavior}

Fertilizing habits

No fertilizer use

1-2 times (base)

More than 3 times

Watering habits

As needed to keep lawn green

Infrequently (base)

Never/ Severe drought

Use lawn care service

No use (base)

Mowing only

Chemical use

Hours spent on gardening/lawn

More than 10 hours

Conducted soil test

\section{Personal Characteristics}

Male

Education

High school degree or GED

$2 y r$ college degree

4yr college degree (base)

Graduate degree

Household income

$\$ 0$ - $\$ 25,000$

$\$ 25,000$ - $\$ 49,999$

$\$ 50,000$ - \$74,999 (base)

$601 \quad 0.567$

$601 \quad 0.285$

0.327

0.303

0.496

0.534

0.452

0.146

$603 \quad 0.264$

$603 \quad 0.420$

0.441

0.211

0.494

0.383

$603 \quad 0.269$

0.444

0.350

$603 \quad 0.635$

0.482

0.750

0.218

0.056

0.194

0.465

0.500

0.641

0.264

$592 \quad 0.147$

0.354

0.472

0.628

0.682

0.659

0.674

$\begin{array}{llll}603 & 0.103 & 0.304 & 0.088\end{array}$

$603 \quad 0.189$

0.392

0.243

$603 \quad 0.350$

0.477

0.326

$603 \quad 0.358$

0.480

0.343

$550 \quad 0.047$

0.212

0.054

$550 \quad 0.171$

0.377

0.226

$550 \quad 0.262$

0.440

0.321

0.112

0.088

0.107

0.161

0.228

0.171

0.360

0.331

0.355

0.367

0.353

0.367 


\section{Continued}

\begin{tabular}{|c|c|c|c|c|c|c|c|}
\hline$\$ 75,000-\$ 99,999$ & 550 & 0.185 & 0.389 & 0.131 & 0.208 & 0.152 & 0.192 \\
\hline$\$ 100,000+$ & 550 & 0.335 & 0.472 & 0.268 & 0.366 & 0.352 & 0.334 \\
\hline Homeownership & 602 & 0.944 & 0.231 & 0.923 & 0.953 & 0.934 & 0.945 \\
\hline \multicolumn{8}{|l|}{ Where you live } \\
\hline Urban area (base) & 605 & 0.648 & 0.478 & 0.619 & 0.664 & 0.647 & 0.651 \\
\hline Suburban area & 605 & 0.236 & 0.425 & 0.199 & 0.252 & 0.235 & 0.238 \\
\hline Rural area & 605 & 0.116 & 0.320 & 0.182 & 0.084 & 0.118 & 0.111 \\
\hline \multicolumn{8}{|l|}{ Information Source } \\
\hline Not applicable & 598 & 0.100 & 0.301 & 0.250 & 0.025 & 0.134 & 0.084 \\
\hline Commercials & 598 & 0.033 & 0.180 & 0.017 & 0.040 & 0.037 & 0.034 \\
\hline Internet & 598 & 0.054 & 0.225 & 0.072 & 0.045 & 0.060 & 0.053 \\
\hline Label & 598 & 0.296 & 0.457 & 0.306 & 0.303 & 0.231 & 0.322 \\
\hline Retail store recommend & 598 & 0.047 & 0.211 & 0.022 & 0.060 & 0.060 & 0.046 \\
\hline Extension/professionals (base) & 598 & 0.161 & 0.367 & 0.094 & 0.190 & 0.201 & 0.146 \\
\hline Neighbors & 598 & 0.112 & 0.316 & 0.089 & 0.128 & 0.082 & 0.126 \\
\hline Others & 598 & 0.197 & 0.398 & 0.150 & 0.210 & 0.194 & 0.189 \\
\hline
\end{tabular}

fertilizer (composted manure)" and 23 percent indicated they used "phosphorous-free fertilizer". Of those using organic fertilizer, about 40 percent also use P-free fertilizer. About 52 percent of those using P-free fertilizer indicated that they also used organic fertilizer. Adopters of each practice tend to have higher knowledge of the watershed concept and to have more environmentally-oriented attitudes. Those who use organic manure tend to be less concerned about their neighbors' opinion of their yards. Across all respondents, 57 percent fertilized 1 - 2 times per year as recommended by University of Missouri Extension staff but only 15 percent had conducted a soil test. This is unfortunate since $\mathrm{P}$ is generally at sufficient levels in established lawns. This rate is slightly lower than the 18 percent rate reported by [30] for New Jersey. The most common watering frequency was infrequently. Almost two-thirds of respondents indicated they never used a lawn service, and those who do were more likely to use them for fertilizer and pesticide applications than mowing. Almost half of respondents indicated that they spent more than 10 hours per month on yardwork during the growing season. We asked the member of the household who did the majority of the yardwork to fill out the survey and two-thirds of respondents were male. The respondents were highly educated with over 70 percent indicating they had at least a four year degree. Census data for the City of Columbia give that number as 55 percent. The most common household income category was over $\$ 100,000$ while the most common one based on Census data is less than $\$ 50,000$. Given that Columbia is a college town and that people living in houses tend to be more educated and wealthier than those living in apartments, this is not unexpected, 
however some bias may exist. Almost 95 percent of respondents owned their home and the majority lived in the City of Columbia. The most common source of information on which fertilizer to use was the product label.

To test for multicollinearity we examined correlation coefficients as well as the variance inflation factor (VIF) for each variable. None of the correlations was higher than 0.5. The VIF for all variables in the models (maximum of 2.21) was below the cutoff of 10 proposed by [45]. Thus there is no evidence of multicollinearity in the bivariate probit regressions. Univariate logit regression results were used to estimate the McFadden pseudo-R2 which was 0.29 for the organic fertilizer model and 0.13 for the P-free model.

As indicated above, it is possible that the adoption decisions for the two practices are correlated so a bivariate probit model was analyzed. The value of rho (which has a possible range of -1 to 1 ) was 0.38 and it was highly significant $(\mathrm{P}<$ $0.01)$ indicating that adoption of one practice is positively correlated with adoption of the other. The analyses shown in Table 2 thus relate to the bivariate probit which accounts for the correlation of the error terms. Variables that are significant at the $\mathrm{P}<0.10$ level or below are discussed. Three variables had a positive effect on adoption of both practices: knowledge of the watershed concept, spending more than 10 hours gardening, and whether they had also adopted soil testing. Adopters thus tend to be serious gardeners who are well-informed on nutrient applications as well as water quality issues. The effect of hours spent gardening was both larger and more significant for organic fertilizer, as expected.

In other cases, the significant variables varied by practice. Those who indicated they never fertilize their lawn were significantly more likely to use organic fertilizer, while those who fertilized more than two times per year were less likely to adopt it. The location of the organic fertilizer use was not indicated so it is possible they do not fertilize their lawns but do fertilize their vegetable or flower gardens. Given the way the survey was designed, we do not know where these two fertilizer products were applied. However, it seems more likely that these people do not consider composted manure to be fertilizer. While better for the environment than typical commercial fertilizer, the $\mathrm{P}$-free product is regarded as fertilizer since it did not vary with fertilization frequency.

Contrary to the organic fertilizer case, one of the variables for environmental attitudes, that protecting water quality is more important than economic growth, was positively associated with adoption of P-free fertilizer. This is in line with our hypotheses about this water quality-specific variable. For organic fertilizer, the variable for trust in environmental groups was very close to significance $(\mathrm{P}<$ 0.1010 ) and was significant before dropping the 66 observations that we deemed to have not used fertilizer of any kind. Those who use a service for mowing were less likely to adopt organic fertilizer and those who use a service that includes chemical application were less likely to use P-free fertilizer.

Some demographic variables also differed by practice. For P-free fertilizer, no demographic variables were significant, again highlighting the fact that its use 
Table 2. Bivariate probit regression results.

\begin{tabular}{|c|c|c|}
\hline Variable & $\begin{array}{l}\text { Organic fertilizer } \\
\text { Coef. }\end{array}$ & $\begin{array}{c}\text { P-free fertilizer } \\
\text { Coef. }\end{array}$ \\
\hline \multicolumn{3}{|l|}{ Environmental Knowledge and Attitudes } \\
\hline Knowledge of watershed & $0.390^{* *}$ & $0.344^{\star *}$ \\
\hline Importance of water quality & 0.097 & $0.422^{* *}$ \\
\hline Concern about neighbors' opinions & -0.198 & -0.100 \\
\hline Trust env. group very much & 0.306 & 0.086 \\
\hline \multicolumn{3}{|l|}{ Yard Management Behavior } \\
\hline \multicolumn{3}{|l|}{ Lawn fertilizing habits (base: 1 - 2 times) } \\
\hline No use of fertilizer & $0.753^{\star * *}$ & -0.445 \\
\hline More than 3 times & $-0.391^{\star *}$ & 0.091 \\
\hline \multicolumn{3}{|c|}{ Lawn watering habits (base: infrequently) } \\
\hline As needed to keep lawn green & 0.209 & 0.286 \\
\hline Never/severe drought & -0.111 & -0.029 \\
\hline \multicolumn{3}{|l|}{ Use lawn care service (base: No use) } \\
\hline Mowing only & $-0.918^{\star}$ & -0.018 \\
\hline Chemical use & -0.333 & $-0.390^{*}$ \\
\hline \multicolumn{3}{|l|}{ Hours spent on gardening/lawn } \\
\hline More than 10 hours & $0.481^{* * *}$ & $0.241^{\star}$ \\
\hline Conducted soil test & $0.988^{* * *}$ & $0.958^{* * *}$ \\
\hline \multicolumn{3}{|l|}{ Personal Characteristics } \\
\hline Male & -0.295 & -0.133 \\
\hline \multicolumn{3}{|l|}{ Education (base: 4 yrs college degree) } \\
\hline High School degree or GED & -0.188 & -0.020 \\
\hline 2 yr college degree & $0.514^{* *}$ & 0.304 \\
\hline Graduate degree & 0.124 & -0.178 \\
\hline \multicolumn{3}{|c|}{ Household income (base: $\$ 50,000$ - $\$ 74,999$ ) } \\
\hline$\$ 0-\$ 25,000$ & -0.073 & -0.394 \\
\hline$\$ 25,000-\$ 49,999$ & -0.044 & -0.077 \\
\hline$\$ 75,000-\$ 99,999$ & $-0.483^{* *}$ & -0.164 \\
\hline$\$ 100,000+$ & -0.231 & 0.022 \\
\hline Homeownership & -0.038 & -0.395 \\
\hline \multicolumn{3}{|l|}{ Where you live (base: Urban area) } \\
\hline Suburban area & -0.091 & -0.101 \\
\hline Rural area & -0.008 & -0.412 \\
\hline \multicolumn{3}{|c|}{ Information Source (Base: Extension/Professionals) } \\
\hline Not applicable & $1.454^{* * *}$ & 0.252 \\
\hline Commercials & 0.113 & -0.040 \\
\hline
\end{tabular}




\begin{tabular}{lcc} 
Continued & & \\
\hline Internet & $0.673^{*}$ & -0.194 \\
Label & 0.161 & -0.408 \\
Retail store recommend & -0.443 & -0.201 \\
Neighbors & 0.054 & $-0.627^{*}$ \\
Others & 0.229 & -0.181 \\
Constant & $-1.071^{* *}$ & -0.731 \\
Goodness of Fit & & \\
N & 489 & 484 \\
Log pseudo likelihood & -215.892 & -226.025 \\
Wald chi2 (30) & 180.568 & 69.196 \\
Prob $>$ chi2 & 0 & 0 \\
Psuedo-R ${ }^{2}$ McFadden) & 0.295 & 0.133 \\
AIC & 493.784 & 514.049 \\
BIC (df $=31$ ) & 623.747 & 643.694 \\
\hline
\end{tabular}

characteristics are very similar to those of balanced fertilizers. This is contrary to the positive income effect and negative gender effect for P-free fertilizers found by [27], but similar to their education result. Those with some college or a two-year degree were more likely to adopt organic fertilizer than those with a B.S. degree. This result is somewhat puzzling but it may be that some of the adopters were current college students and it is in line with the findings of [29]. Those earning $\$ 75,000$ - 99,999 were less likely than those with a household income of $\$ 50,000$ 74,999 to use organic fertilizer. Again, use of this environmental practice does not seem to conform to the general findings of the literature, but it may be linked to the opportunity cost of time for this group since commercial fertilizer is easier to obtain and use relative to composted manure. Neither homeownership nor location of the home affected adoption of either practice, ceteris paribus. Given that no permanent landscape changes are required, the homeownership result is not surprising. We had expected rural households to be more aware of manure and thus more likely to use it. Reference [29] had found that rural households were more likely to use rain barrels than urban ones and [46] had found rural residents were more likely to plant drought tolerant plants.

The two practices also differed with respect to preferred sources of information. Compared to those whose preferred source for fertilizer information was professionals/Extension, adopters of organic manure were more likely to prefer the internet and to indicate "not applicable". Again, those who adopt composted manure do not seem to view it as a fertilizer. Adopters of P-free fertilizer were less likely to consult neighbors than the base category of professionals or Extension.

For both practices, adopters are knowledgeable about water quality in general as proxied by their knowledge of the watershed concept, as well as being in- 
formed about the nutrient status of their own landscape as evidenced by their use of soil testing. They are also serious gardeners who tend to take care of their lawn and garden themselves. From responses to the fertilizer frequency question as well as the question on sources of information, organic fertilizer users do not seem to regard the product as a fertilizer. Demographic variables had little explanatory power for P-free fertilizer. The effect of demographic variables for organic fertilizer was not linear but rather adopters tended to have levels of education and income that were in the middle of the range of categories. Given some of our other research on water management practices (e.g. [29]), the lack of effect of home location for either practice was interesting. The results regarding preferred sources of information indicate that those using organic fertilizer may either distrust standard sources of information or do not find them helpful so they use the internet. This has implications for producers of organic fertilizers; advertising on the internet may be a good way to reach these households. Those using P-free fertilizer do seem to trust traditional information sources such as Extension staff or horticulture professionals as much as other sources of information and more than neighbors. Additional educational efforts oriented to households regarding fertilizers and soil testing may be warranted.

\section{Conclusions and Implications}

These results seem to indicate that adoption of these practices is likely driven in part by a desire to improve the environment but that these people are also keen, well-informed gardeners. Making these products both available and prominent at gardening supply stores may increase adoption rates since adopters would tend to buy plants and seeds as well as fertilizers at these stores. Educators could emphasize the importance of soil tests since it is positively associated with adoption of these practices but also because adoption of soil testing is quite low in the US and P levels in urban soils tend to be high. Presentations at gardening clubs might increase adoption of P-free fertilizers among gardeners who are concerned with the appearance of their lawns and gardens. Presentations that target those who want to use natural products may need to indicate that $\mathrm{P}$ build-up could occur with the use of composted manures. Some adopters may be unwilling to supplement this product with commercial $\mathrm{N}$ sources but based on the fact that there was joint adoption of the two practices, complementing organic fertilizer with P-free fertilizer may be a beneficial strategy. Educational efforts aimed at homeowners must recognize that they may have multiple goals that may potentially be in conflict. Homeowners may want to be environmentally friendly but they also want an attractive lawn and garden [25].

Educational programs targeted to lawn care companies might be very useful since most companies apply the same types and rates of fertilizers to all lawns in their service areas and do not typically conduct soil tests to identify fertilizer needs [46]. Educating landscape professionals may be one way to affect fertilizer management of households who would otherwise be hard to reach since they are 
not particularly interested in gardening. For those who are nevertheless interested in helping the environment, a tailored, eco-friendly service might be a potential niche market for some of the independent companies.

Since the use of P-free fertilizers seems to have little down-side for households with established lawns but $P$ runoff from urban areas is a problem, and given the large number of fertilizer options available at home improvement and gardening supply stores, regulations limiting access to lawn fertilizers with $\mathrm{P}$ may be reasonable. The default for households would thus change from a balanced fertilizer like 10-10-10 to one that only supplied nitrogen or nitrogen and potassium. At the very least, sellers could be encouraged to display P-free fertilizers more prominently so those who grab the first bag of fertilizer they see on the endcap, buy the product that is better for the environment.

\section{Acknowledgements}

This project was supported by National Integrated Water Quality Grant Program number 110.C (Award 2012-03652). The authors would like to thank Deanna Osmond, Robert Broz, Brad Fresenburg and Mike Heimos for constructive comments. The authors also acknowledge the support of the Missouri Agricultural Experiment Station.

\section{References}

[1] US Department of Agriculture (2013) Summary Report: 2010 National Resources Inventory. Natural Resources Conservation Service, US Department of Agriculture, Washington, DC.

[2] United Nations, Department of Economic and Social Affairs, Population Division (2014) Highlights, World Urbanization Trends 2014: Key Facts. https://esa.un.org/unpd/wup/Publications/Files/WUP2014-Highlights.pdf

[3] Chesapeake Bay Program (2010) Bay Barometer: A Health and Restoration Assessment of the Chesapeake Bay and Watershed in 2009. Annapolis, MD.

[4] Robbins, P. and Birkenholtz, T. (2003) Turfgrass Revolution: Measuring the Expansion of the American Lawn. Land Use Policy, 20, 181-194.

https://doi.org/10.1016/S0264-8377(03)00006-1

[5] Jenkins, V.S. (1994) The Lawn: A History of an American Obsession. Smithsonian Institution Press, Washington, DC.

[6] Dietz, M.E., Clausen, J.C. and Filchak, K.K. (2004) Education and Changes in Residential Nonpoint Source Pollution. Environmental Management, 34, 684-690. https://doi.org/10.1007/s00267-003-0238-4

[7] Hefner, S.G., Robertson, C., Coulter, A. and Stevens, G. (2009) Engaging Citizens to Urban Nutrient Planning of Lawns within a Nutrient Sensitive Watershed. Journal of Extension, 47, Article ID: 4IAW5.

[8] Sewell, S., McCallister, D., Gaussoin, R. and Wortmann, C. (2010). Lawn Management Practices and Perceptions of Residents in 14 Sandpit Lakes of Nebraska. Journal of Extension, 48, Article ID: 2RIB4. http://www.joe.org/joe/2010april/rb4.php

[9] Nathan, M. (2010) Soil Test Summary for Urban Lawns and Gardens Soils. Missouri Environment and Garden, 16. 
[10] Swann, C.P. (2000) A Survey of Nutrient Behavior among Residents in the Chesapeake Bay Watershed. Proceedings of the National Conference on Tools of Urban Water Resource Management and Protection, Chicago, 7-10 February 2000, 230-237.

[11] Abdalla, C.W. and Lawton, J.L. (2006) Environmental Issues in Animal Agriculture. Choices, 21, 177-182.

[12] Ribaudo, M., Delgado, J., Hansen, L., Livingston, M., Mosheim, R. and Williamson, J. (2011) Nitrogen in Agricultural Systems: Implications for Conservation Policy. USDA-ERS, Economic Research Report Number 127. https://doi.org/10.2139/ssrn.2115532

[13] Smith, R.A., Schwarz, G.E. and Alexander, R.B. (1997) SPARROW Surface Water-Quality Modeling Nutrients in Watersheds of the Conterminous United States: Model Predictions for Total Nitrogen (TN) and Total Phosphorous (TP). http://water.usgs.gov/nawqa/sparrow/wrr97/results.html

[14] Ribaudo, M.O., Gollehon, N.R. and Agapoff, J. (2003). Land Application of Manure by Animal Feeding Operations: Is More Land Needed? Journal of Soil and Water Conservation, 58, 30-38.

[15] Carreira, R.I., Young, K.B., Goodwin, H.L. and Wailes, E.J. (2007) How Far Can Poultry Litter Go? A New Technology for Litter Transport. Journal of Agricultural and Applied Economics, 39, 611-623. https://doi.org/10.1017/S1074070800023300

[16] Ali, S., McCann, L. and Allspach, J. (2012) Manure Transfers in the Midwest and Factors Affecting Adoption of Manure Testing. Journal of Agricultural and Applied Economics, 44, 533-548. https://doi.org/10.1017/S1074070800024093

[17] Lehman, J.T., Bell, D.W. and McDonald, K.E. (2009) Reduced River Phosphorous Following Implementation of a Lawn Fertilizer Ordinance. Lake and Reservoir Management, 25, 307-312. https://doi.org/10.1080/07438140903117217

[18] Miller, K. (2012) State Laws Banning Phosphorous Fertilizer Use. 2012-R-0076. Connecticut General Assembly, Office of Legislative Research, Hartford, 1-4.

[19] Lehman, J.T., Bell, D.W., Doubek, J.P. and McDonald, K.E. (2011) Reduced Additions to River Phosphorous for Three Years Following Implementation of a Lawn Fertilizer Ordinance. Lake and Reservoir Management, 27, 390-397. https://doi.org/10.1080/07438141.2011.629769

[20] Feder, G. and Umali, D.L. (1993) The Adoption of Agricultural Innovations: A Review. Technological Forecasting and Social Change, 43, 215-239. https://doi.org/10.1016/0040-1625(93)90053-A

[21] Prokopy, L.S., Genskow, K., Asher, J., Baumgart-Getz, A., Bonnell, J., Broussard, S., Curtis, C., Floress, K., McDermaid, K., Power, R. and Wood, D. (2009) Designing a Regional System of Social Indicators to Evaluate Nonpoint Source Water Projects. Journal of Extension, 47, 8.

[22] Rogers, E.M. (1995) Diffusion of Innovations. The Free Press, New York.

[23] Stoneman, P. (2002) The Economics of Technological Diffusion. Blackwell Publishers Ltd., Oxford.

[24] Ando, A.W. and Freitas, L. (2011) Consumer Demand for Green Stormwater Management Technology in an Urban Setting: The Case of Chicago Rain Barrels. Water Resources Research, 47, W12501. https://doi.org/10.1029/2011WR011070

[25] Blaine, T.W., Clayton, S., Robbins, P. and Grewal, P.S. (2012) Homeowner Attitudes and Practices towards Residential Landscape Management in Ohio, USA. Environmental Management, 50, 257-271. https://doi.org/10.1007/s00267-012-9874-X

[26] Boyer, T.A., Kanza, P., Ghimire, M. and Moss, J.Q. (2015) Household Adoption of 
Water Conservation and Resilience under Drought: The Case of Oklahoma City. Water Economics and Policy, 1, 1-21.

[27] Brehm, J.M., Pasko, D.K. and Eisenhauer, B.W. (2013) Identifying Key Factors in Homeowner's Adoption of Water Quality Best Management Practices. Environmental Management, 52, 113-122. https://doi.org/10.1007/s00267-013-0056-2

[28] Osmond, D.L. and Hardy, D.H. (2004) Characterization of Turf Practices in Five North Carolina Communities. Journal of Environmental Quality, 33, 565-575. https://doi.org/10.2134/jeq2004.5650

[29] Shin, D.W. and McCann, L. (2017) Enhancing Adoption Studies: The Case of Residential Stormwater Management Practices in the Midwest. Agricultural and Resource Economics Review. https://doi.org/10.1017/age.2017.3

[30] Mangiafico, S.S., Obropta, C.C. and Rossi-Griffin, E. (2012) Demographic Factors Influence Environmental Values: A Lawn-Care Survey of Homeowners in New Jersey. The Journal of Extension, 50, 1RIB6.

[31] Newburn, D., Alberini, A., Rockler, A. and Karp, A. (2014) Adoption of Household Stormwater Best Management Practices. CANRP Extension Bulletins, University of Maryland, College Park.

[32] Purchase, M. (1997) Factors That Influence the Adoption of Lawn Alternative Residential Landscapes. Unpublished Master's Thesis, University of Guelph, Guelph.

[33] Warner, L.A., Lamm, A.J. and Chaudhary, A.K. (2018) Florida Residents' Perceived Role in Protecting Water Quantity and Quality through Landscape Practices. Landscape and Urban Planning, 171, 1-6. https://doi.org/10.1016/j.landurbplan.2017.11.007

[34] Martini, N.F., Nelson, K.C., Hobbie, S.E. and Baker, L.A. (2015) Why Feed the Lawn? Exploring the Influences on Residential Turf Grass Fertilization in the Minneapolis-Saint Paul Metropolitan Area. Environment and Behavior, 47, 158-183. https://doi.org/10.1177/0013916513492418

[35] Jorgensen, B.S. and Syme, G.J. (2000) Protest Responses and Willingness to Pay: Attitude toward Paying for Stormwater Pollution Abatement. Ecological Economics, 33, 251-265. https://doi.org/10.1016/S0921-8009(99)00145-7

[36] Bakacs, M.E., Haberland, M., Mangiafico, S.S., Winquist, A., Obropta, C.C., Boyajian, A. and Mellor, S. (2013) Rain Barrels: A Catalyst for Change. Journal of Extension, 51, 3RIB6.

[37] Varlamoff, S., Florkowski, W.J., Jordan, J.L., Latimer, J. and Braman, K. (2001) Georgia Homeowner Survey of Landscape Management Practices. HortTechnology, 11, 326-331.

[38] Staab, J.M. and Iannacchione, V.G. (2003) Evaluating the Use of Residential Mailing Addresses in a National Household Survey. In: Proceedings of the Survey Research Methods Section of the American Statistical Association, American Statistical Association, Alexandria, 4028-4033.

[39] Dillman, D.A. (2011) Mail and Internet Surveys: The Tailored Design Method. 2nd Edition, John Wiley \& Sons, Inc., Hoboken.

[40] Baumer, M.D. (2007) Attitudes, Awareness and Actions of the Residents of the Hinkson Creek Watershed Regarding Water Quality and Environmentalism. M.S. Thesis, Department of Rural Sociology, University of Missouri, Columbia.

[41] Meyer, M.H., Behe, B.K. and Heilig, J. (2001) The Economic Impact and Perceived Environmental Effect of Home Lawns in Minnesota. HortTechnology, 11, 585-590.

[42] Genskow, K. and Prokopy, L.S. (2009) Lessons Learned in Developing Social Indi- 
cators for Regional Water Quality Management. Society \& Natural Resources, 23, 83-91. https://doi.org/10.1080/08941920802388961

[43] DeMaio, T.J., Rothgeb, J. and Hess, J. (1998) Improving Survey Quality through Pretesting. In: Proceedings of the Section on Survey Research Methods, American Statistical Association, Alexandria, Vol. 3, 50-58.

[44] Greene, W.H. (2003) Econometric Analysis. Pearson Education India, Kerala.

[45] Hair, J.F., Black, W.C., Babin, B.J., Anderson, R.E. and Tatham, R.L. (2006) Multivariate Data Analysis. Vol. 6, Pearson Prentice Hall, Upper Saddle River.

[46] Fan, Y., McCann, L. and Qin, H. (2017) Households' Adoption of Drought Tolerant Plants: An Adaptation to Climate Change? Journal of Agricultural and Resource Economics, 42, 236-254. 